\title{
Measuring Performance in Egyptian Construction Firms Applying Quality Management Systems
}

\author{
Manal S. Abd Elhamid ${ }^{1}$ and Sahar. Sh. Ghareeb ${ }^{2}$
}

\begin{abstract}
Egyptian construction firms (ECF) started recently to adopt quality management system (QMS) as a way to develop and improve their performance as previous studies have shown. However, considering all the firm's aspects in a competitive way is a crucial process for the ECF's culture. This research is trying to indicate the role of the QMS implementation in measuring performance (MP) through developing a model for measuring performance at the organizational level, and to explore its impact on the organizations that adopt QMS. This model is based on specific elements and their related indicators which have been derived from national approaches and models of MP. This model determines the performance level $(P L)$ of the organization that is measured by means of a point system. Weights of the elements in the point system considered both the elements' importance in the international models and its real practice in the ECFs. This model has been validated using another questionnaire and the majority of surveyed experts agreed that the proposed model can be applied effectively.
\end{abstract}

Keywords: Measuring Performance; Quality Management Systems; Performance level; Egyptian Construction firms

\section{INTRODUCTION}

Nowadays, the construction market has become a global market, which has different customers and many competitors. This environment represents a challenge for the ECF to earn a significant place in that market and even more of a challenge to improve it. Since it is not possible to manage what cannot be measured, the ECFs have recently adopted QMS as a way to develop and improve their performance. While considering all the firm's aspects in a competitive way by means of measuring performance should be a crucial process for the ECF's culture, the ECF's culture generally employs such systems to be a mere marketing tool rather than a system for improving and measuring performance. Therefore the need for the research arises to answer the following questions: how does adopting QMS influence the process of MP and how can it be employed to enable the ECFs to measure their performance?. Based on this, the study is aimed at achieving the following objectives: 1) Identifying the role of QMS implementation such as ISO 9001 and TQM as a tool to achieve improvement in MP, 2) Exploring the influence of QMS implementation on Performance Measurement in ECFs, 3) Developing a model for measuring performance -based on the previous findingsthat take into consideration the local practices and the international approaches for measuring performance such as, Benchmarking, Quality Awards and Six Sigma.

\section{LITERATURE REVIEW}

Definitions and principals of QMS and MP models (MPM) are reviewed for a comprehensive understanding of this relation.
- The reviewed literature has introduced the following definitions:

Quality Management System (QMS): In defining QMS, Oakland [1], stated that "a firm organizes itself in such a way that the human, administrative and technical factors affecting quality will be under control, this leads to the requirement for the development and implementation of a quality management system that enables the objectives set out in the quality policy to be accomplished. Abd Elhamid [2] developed a QMS by integration between ISO 9000 and TQM

Performance Measurement in construction: Alarcon and Ashely [3], in their study explored a variety of PM frameworks that have been implemented in construction since 1990 . They proposed the concept of MP, which was classified into cost, schedule, value, and effectiveness. On the other hand, Eccles [4] had pointed out the limitation of business performance measurement using only financial indicators. Abdel-Razek [5], defines MP as the natural part of analysis, control, evaluation, and management process. Key Performance indicators (KPIs): Cox et al.[6],explains the key performance indicators(KPIs) as the compilations of data used to asses the performance of a construction operation in a simplified way to gather only that data which directly predicts performance for the task to be measured. This can be defined by either quantitative results of a construction process (\$/unit), or by qualitative measures.

- Different approaches for identifying performance measures are studied as following:

\footnotetext{
1 Associate Professor of Construction Project Management-Housing \& Building National Research Center, Cairo, Egypt, hamidmanal@yahoo.com (*Coressponding Author)

2 Lecturer assistant of Construction Project Management-Housing and Building National Research Center, Cairo, Egypt, eng_sahar5 @yahoo.com
} 
Motwani [7] offers in his study a set of critical factors / dimensions and more than 45 supporting performance measures of TQM based on extensive review of prescriptive, conceptual, practitioner, and empirical literature. Oakland [1] introduced some critical elements of good performance measurement framework (PMF); including: Leadership and commitment, full employee, good planning, sound implementation strategy, measurement and evaluation, control and improvement, achieving and maintaining standards of excellence.

Another study by Mossallam [8], proposed a framework which links the indicators of performance with the firm's activities, in a way that makes it easy to be implemented and conducted by the firm to evaluate its own performance. This framework is based on the idea of relating the core, supporting, and complementary processes to organizational performance. These indicators are no more than the items that can be measured and controlled within the core, supporting, and complementary activities aiming to the improvement of the current performance. But he dose not take the principles of QMS into consideration.

From these different approaches for identifying performance measures and National Models for QMS [2]; this study has come out with the most common and critical elements of MP and their indicators which are calculated and tabulated in Table 8. These elements and related indicators will constitute the body of the proposed model that will determine the performance level (PL) of the organization that is measured by means of a point system considering both the elements importance in the international models and its real practice in the ECFs.

\section{METHODOLOGY}

To achieve the research objectives, as a preliminary step a theoretical study took place to get a comprehensive picture about the implemented QMS and MPM locally and globally, and to identify the elements and their indicators for MP. Based on that, a field study was conducted through surveying, by means of questionnaire distributed to a representative sample of ECFs [9]. The questionnaire was designed to investigate both the implemented QMS and the applied measuring performance process in ECF, first to investigate the status of measuring performance in construction firms and investigate the status of elements' real practice, and second to see how it is influenced by the implementation of QMS.

The questionnaire design went through these stages:

- Initial design of format, questions and scale

- Distributing the questionnaire to a pilot sample of seven construction firms; which were characterized by good experience and a background of total quality and implementation of measuring principles in order to positively improve the questionnaire. Piloting was carried out by personal interview.
- To distribute the questionnaire; a random sample of construction companies were selected from a manual of The Egyptian Federation for Construction and Building Contractors.

- The survey was carried out in the Greater Cairo region which includes not only the capital but also the governorates of Giza and El-Qalyobia where most of the medium to large, public and private construction firms that are more likely to adopt QMS exist.

- The questionnaires were answered by one of the representative officials in the firm, either the project manager, or the head of sector or the technical office manager (since they have a higher level of management knowledge and their positions enable them to be fully aware of the firm's performance).

- The questionnaire was adjusted based on the pilot sample feedback

Determination of sample size: The sample size has been determined [10], according to the following equation:

$$
\mathrm{n}_{0}=\frac{\mathrm{z}^{2} \mathrm{pq}}{\mathrm{e}^{2}}
$$

Where:

$\mathrm{n}_{0}$ is the sample size .

$\mathrm{Z}$ is the abscissa of the normal curve for desired confidence level.

$\mathrm{e}$ is the desired level of precision .

$\mathrm{p}$ is the estimated proportion of an attribute that is present in the population, $\mathrm{q}$ is $1-\mathrm{p}$.

At confidence level 90\%, $\mathrm{z}=1.64$

The desired level of precision is $+10 \%$, so $\mathrm{e}=0.1$

Assume $\mathrm{p}=0.5$ (maximum variability), $\mathrm{q}=1-\mathrm{p}=0.5$

$\mathrm{n}_{0}=\frac{(1.64)^{2}(0.5)(0.5)}{(0.1)^{2}}=68$

The sample size $\left(\mathrm{n}_{0}\right)$ can be adjusted using equation:

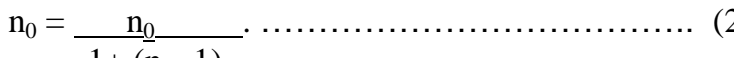

$$
\begin{aligned}
& 1+\underline{\left(\mathrm{n}_{0}\right.} \frac{-1)}{\mathrm{N}}
\end{aligned}
$$

Where, $\mathrm{N}$ is the population size $=3000$ (main construction firms in great Cairo region.).

$$
\mathrm{n}_{0}=\frac{68}{1+((68-1) / 3000)}=66.5=67 \text { companies }
$$

Commonly the calculated sample size is increased by $30 \sim 40 \%$ to compensate for no response, therefore total number of 140 questionnaires were randomly distributed on Egyptian construction firms in general- whether applying QMS or not-(limited to great Cairo region) [9]. A total of 89 out of 140 questionnaires were returned with response rate $63.6 \% .13$ of them are rejected and finally 76 questionnaires were ready to be analyzed using SPSS computer program.

\section{DATA ANALYSIS, RESUlts AND DisCUSSION}

\section{A. Sample profile}

Description analysis has been conducted to identify sample profile; Most of the surveyed firms are large in "experience and annual work size". The majority is 
specialized in execution works $(88 \%)$, while design and management firms are represented equally in the sample with approximately (47.4\%).The private firms have the largest share in the surveyed sample, as shown in Fig. (1), which represents the distribution of the firms in the sample with respect to their types. The sample profile regarding the firm type resamples the distribution of construction firms in the real population in Egypt

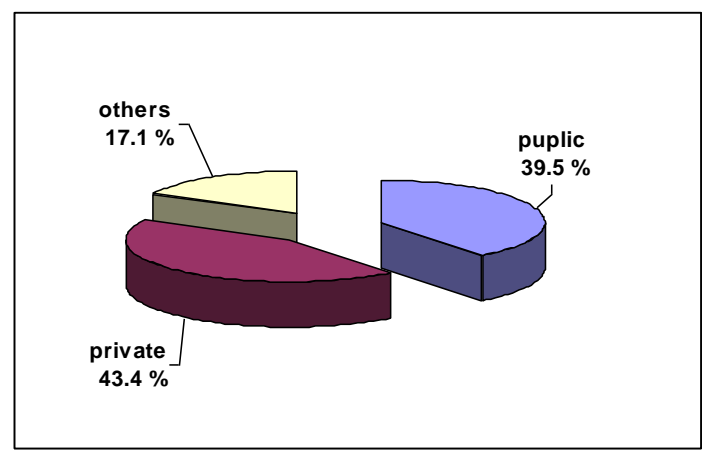

FIGURE 1

DISTRIBUTION OF RESPONDENTS BY FIRM TYPE

\section{B. Implemented QMS}

The survey has found that ISO 9001 is the most applied QMS in ECFs representing 51.3\% of the respondent firms, while just $7.9 \%$ of them apply TQM, and $26.3 \%$ apply other systems such as ISO 14001 and 17025 and most of them have their own quality management systems as shown in Fig. (2). The respondents were asked to choose the level of application of QMS in their firms according to an increasing scale from 'do not apply" to 'apply perfectly". This categorization has been judged depending on how seriously the firm implements QMS, and whether it applies all the principles or part of them.

They were also asked to select the degree of contribution of QMS implementation in improving the performance in their firms as well. Fig. 3 represents the relationship between QMS level of application and its contribution in performance improvement. The Figure shows a positive and approximately linear relationship .The questionnaire also asked about the criteria used by ECF for evaluating the implemented QMS; the respondents were allowed to choose one or more answer. The answers revealed that there are five criteria which exceed $40 \%$ of total responses which are: financial measures, coordination between stakeholders, leadership commitment, success in using resources, and customer satisfaction respectively. On the other hand, criteria such as competition, process management, information technology and impact on society have considerably lower percentages.

\section{Correlations between firm characteristics and QMS:}

A correlation test using Pearson chi - square statistic; has been conducted to examine if the application of QMS is significantly influenced by the firm's characteristics

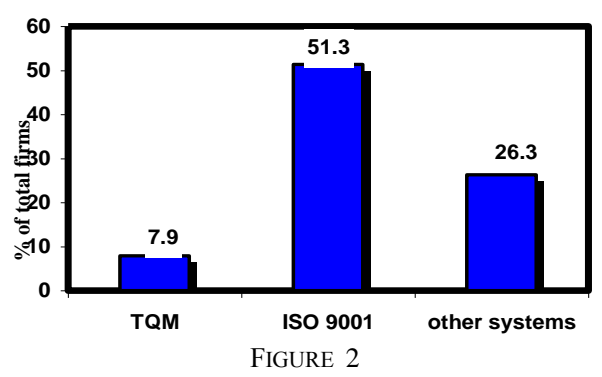

IMPLEMENTED QMS IN EGYPTIAN CONSTRUCTION FIRMS

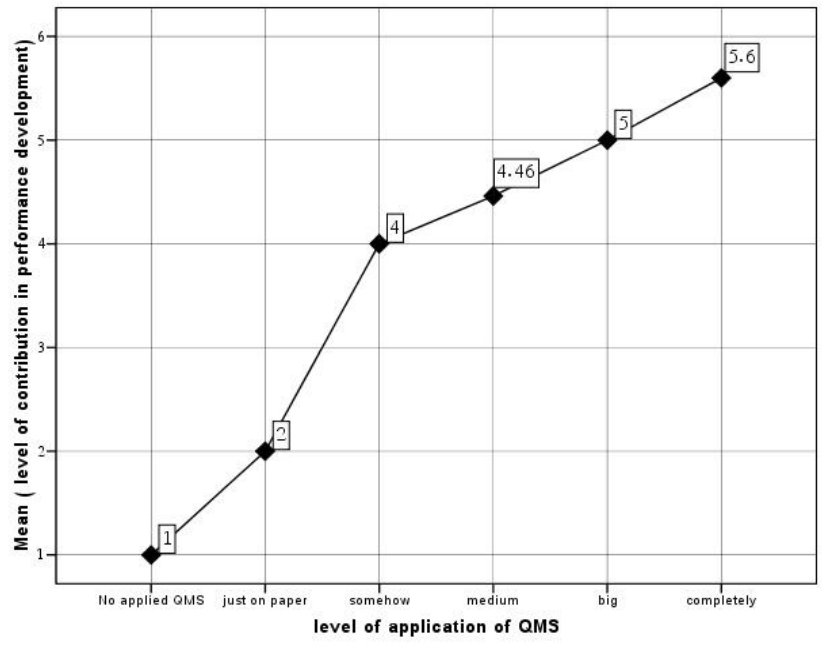

FIGURE 3

RELATION BETWEEN QMS IMPLEMENTATION AND PERFORMANCE IMPROVEMENT.

and the results show that there are high correlations between the applied QMS and the firm type, experience and annual work size, while there is no influence for specialty as shown in Table 1.

TABLE 1

CORRELATION BETWEEN FIRM CHARACTERISTICS AND THE APPLIED QMS

\begin{tabular}{|l|c|c|}
\hline \multirow{2}{*}{\multicolumn{2}{|c|}{ Firm characteristics }} & \multicolumn{2}{|c|}{$\begin{array}{r}\text { pearson chi square for applied } \\
\text { (TQM , ISO 9001, their own } \\
\text { system) }\end{array}$} \\
\cline { 2 - 4 } & Value & Sig. (2-tailed) \\
\hline firm type & 33.747 & $0.004^{*}$ \\
\hline experience & 28.624 & $0.018^{*}$ \\
\hline Type of work(specialty) & 45.935 & 0.803 \\
\hline $\begin{array}{l}\text { work size(in million EGY- } \\
\text { pound) }\end{array}$ & 35.569 & $0.017^{*}$ \\
\hline
\end{tabular}

*: correlation is significant at 0.05 level

By frequency analysis for the classification of the firm's characteristics Table (2); the results assure that QMS are more likely to be applied in public, large and more experience firms. This reflects the need for financial and managerial support to implement and be certified for a system such as ISO 9001 
TABLE 2

FIRM'S CHARACTERISTICS AND THE APPLIED QMS

\begin{tabular}{|c|c|c|c|c|}
\hline \multirow{2}{*}{ Firm's characteristics } & \multicolumn{3}{|c|}{ \% firms applying QMS } & \multirow{2}{*}{$\begin{array}{l}\text { Total no. } \\
\text { of firms }\end{array}$} \\
\hline & TQM & ISO 9001 & OTHERS & \\
\hline Firm Type & \multirow[b]{2}{*}{$3.3 \%$} & \multirow[b]{2}{*}{$\underline{76.7 \%}$} & \multirow[b]{2}{*}{$20.0 \%$} & \multirow[b]{2}{*}{30} \\
\hline Public & & & & \\
\hline private & $12.1 \%$ & $30.3 \%$ & $27.3 \%$ & 33 \\
\hline other firms & $25.0 \%$ & $46.2 \%$ & $55.6 \%$ & 13 \\
\hline Total & & & & 76 \\
\hline \multicolumn{5}{|l|}{ Years of experience } \\
\hline $5 \leq$ years $\leq 10$ & $16.7 \%$ & $0.0 \%$ & $50.0 \%$ & 6 \\
\hline $10<y e a r s \leq 20$ & $0.0 \%$ & $20.0 \%$ & $40.0 \%$ & 15 \\
\hline years > 20 & $9.1 \%$ & $65.5 \%$ & $20.0 \%$ & 55 \\
\hline Total & & & & 76 \\
\hline \multicolumn{5}{|l|}{ Firm size } \\
\hline Large & $9.5 \%$ & $\underline{71.4 \%}$ & $21.4 \%$ & 21 \\
\hline Medium & $4 \%$ & $28.0 \%$ & $32.0 \%$ & 21 \\
\hline Small & $11.1 \%$ & $22.2 \%$ & $33.3 \%$ & 34 \\
\hline Total & & & & 76 \\
\hline
\end{tabular}

\section{The Relative importance of MP elements:}

The respondents were asked to rank from one to ten a list of measuring elements according to their importancefrom their point of view-in the process of MP.

Accordingly, the relative importance index (RII) was calculated using the following formula"(3)".

$$
\mathrm{RII}=\frac{\Sigma \mathrm{P}_{\mathrm{i}} \mathrm{U}_{\mathrm{i}}}{\mathrm{N}}
$$

Where:

$\mathrm{RII}=$ relative importance index

$\mathrm{P}_{\mathrm{i}}=$ respondent's rating (score) which ranges from 1 to 10

$\mathrm{U}_{\mathrm{i}}=$ number of respondents placing identical weighting / rating for element

$\mathrm{N}=$ total number of respondents

$\mathrm{n}=$ the highest attainable score $=10$

RII of the elements ranking are displayed in Table 3.

The analysis of the results in Table (3) reveals that elements that are directly related to financial processes are weighted as the most important measures. While the elements related to planning and design have a lesser degree of importance and at last come the elements of training, safety and supplier quality management, which reflect the dominant culture in ECFs which care more about the short term targets that are directly oriented to quantitative measures.

The questionnaire attained the responses from different groups, where the respondents were from public, private and other firms (investment and join venture firms) as shown in Fig. (1). Therefore, to determine whether there is a significant degree of agreement among the three groups of respondents regarding the RII of each elements; the Spearman's rank correlation coefficient $(\rho)$ was applied [11]. The Spearman's rank correlation coefficient $(\rho)$ was calculated using equation (4)

$$
\rho=\frac{1-6 \Sigma d^{2}}{n\left(n^{2}-1\right)}
$$

Where:

$\mathrm{d}=$ the difference between the ranks given by any two respondents for an individual cause and

$\mathrm{n}=$ the number of causes, which in this case is 10 elements

The results are displayed in Table (4). The rank correlation coefficients for the elements are: 0.78 for "public and private", 0.76 for "public and others", and 0.96 for "private and others". These indicate a significant degree of agreement between the rankings of different groups of respondents.

It is interesting to notice that both private and other firms have ranked the element of "customer satisfaction" as the most important measuring element. While this rank has been declined to the forth by the public firms which reflects the dominating culture of the public firms in Egypt, one which underestimates the value of customer satisfaction in measuring performance.

TABLE 3

RANKING OF ELEMENTS ACCORDING TO THEIR RELATIVE

\begin{tabular}{|c|c|c|c|}
\hline Element & RII & Rank & $\begin{array}{l}\text { Degree of } \\
\text { importance }\end{array}$ \\
\hline Top management and leadership. & 0.85 & 1 & \multirow{4}{*}{$\begin{array}{c}\text { very } \\
\text { important }\end{array}$} \\
\hline Customer satisfaction. & 0.84 & 2 & \\
\hline Productivity and finance. & 0.79 & 3 & \\
\hline Process management. & 0.76 & 4 & \\
\hline Resource management & 0.69 & 5 & \multirow{3}{*}{ important } \\
\hline $\begin{array}{l}\text { Quality measurement and } \\
\text { benchmarking. }\end{array}$ & 0.68 & 6 & \\
\hline Product design and manufacturing & 0.67 & 7 & \\
\hline employee training and empowerment & 0.56 & 8 & \multirow{3}{*}{$\begin{array}{c}\text { Less } \\
\text { important }\end{array}$} \\
\hline Supplier quality management. & 0.52 & 9 & \\
\hline Safety. & 0.45 & 10 & \\
\hline
\end{tabular}
IMPORTANCE

TABLE 4

THE RELATIVE IMPORTANT INDEX OF ELEMENTS FOR DIFFERENT GROUPS

\begin{tabular}{|l|c|c|c|c|c|c|}
\hline \multirow{2}{*}{ Elements } & \multicolumn{2}{|c|}{ PUPLIC } & \multicolumn{2}{c|}{ PRIVATE } & \multicolumn{2}{c|}{ OTHERS } \\
\cline { 2 - 8 } & RII & rank & RII & rank & RII & rank \\
\hline top management leadership. & 0.852 & 1 & 0.840 & 2 & 0.842 & 2 \\
\hline quality measurement and benchmarking. & 0.671 & 5 & 0.624 & 7 & 0.669 & 7 \\
\hline process management. & 0.754 & 2 & 0.783 & 4 & 0.717 & 5 \\
\hline Product design and manufacturing. & 0.620 & 8 & 0.752 & 5 & 0.711 & 6 \\
\hline employee training and empowerment & 0.621 & 7 & 0.507 & 9 & 0.550 & 9 \\
\hline Safety & 0.496 & 9 & 0.407 & 10 & 0.442 & 10 \\
\hline Productivity ad finance. & 0.752 & 3 & 0.811 & 3 & 0.817 & 3 \\
\hline Resource management. & 0.664 & 6 & 0.661 & 6 & 0.738 & 4 \\
\hline Supplier quality management. & 0.465 & 10 & 0.535 & 8 & 0.583 & 8 \\
\hline Customer satisfaction & 0.748 & 4 & 0.876 & 1 & 0.931 & 1 \\
\hline
\end{tabular}




\section{E. Reliability analysis}

The reliability of the surveyed data concerning the elements and their related indicators was tested. This test was conducted using one of the most commonly used reliability coefficients Cronbach's alpha $(\propto)$,to determine how each item reflects the reliability of the scale by calculating the coefficient alpha after deleting each variable independently from the scale. It was found that $(\propto)$ for defining the elements of MP in ECFs is 0.872; indicating that this scale is reasonably reliable. And it is found to be very close to the value based on standardized items. Table (5) shows the average values of $\propto$ if Item deleted, where it can be noticed that most of the elements have values lower than $(0.872)$; referring to their positive effect on the measuring performance.

TABLE 5

ELEMENTS STATISTICS - $(\propto)$ IF ITEM DELETED

\begin{tabular}{|l|c|}
\hline the element & $(\propto)$ if Item Deleted \\
\hline Top management leadership. & 0.878 \\
\hline $\begin{array}{l}\text { Quality measurement and } \\
\text { benchmarking. }\end{array}$ & 0.863 \\
\hline Process management. & 0.862 \\
\hline Product design and manufacturing. & 0.853 \\
\hline employee training and empowerment & 0.856 \\
\hline Safety & 0.853 \\
\hline Productivity ad finance. & 0.863 \\
\hline Resource management. & 0.848 \\
\hline Supplier quality management. & 0.844 \\
\hline Customer satisfaction & 0.875 \\
\hline
\end{tabular}

The previous process of $\propto$ was applied on the indicators as well, and indicated a re liable scale, and reflects their importance in measuring performance in construction firms.

\section{F. The influence of QMS on measuring elements and their indicators:}

A correlation test was conducted to examine whether the measured indicators are significantly influenced by the implemented QMS and/or by QMS' degree of implementation. The Pearson chi-square statistic was used to measure the correlation. Results have been summarized in Table 8. By reviewing columns (5) in Table (8); it shows that applying QMS has a significant influence on twelve indicators that showed a lesser degree of practice in column (4). And there are fifteen indicators (lined and bold ones) which are significantly influenced by the degree of QMS implementation; five out of these belong to the elements "quality measurement and benchmarking" and "Product design and manufacturing". This leads to the conclusion that adopting QMS enhances MP through qualitative and subjective indicators. Also most of the fifteen indicators have high frequencies in their elements, which means that the more emphasis the firms put in measuring these indicators the higher the level of QMS implementation the firms achieve which reflects a mutual influence between MP process and QMS implementation. It can also be noticed that there is some common indicators (Time required for preparing the project quality plan, application of quality management systems, overhead cost reduction, reducing material handling, design quality, and accidents' frequency) that are influenced by both the implementing QMS and their degree of implementation, which reflects the importance of applying QMS for improving the weak areas in the culture of ECF's

\section{G. Areas of measuring performance (where to measure?)}

The respondents were asked to select their firms' level of measuring performance for different areas (human resources, materials, equipments, information and the product) according to the scale as shown in Table (6).

TABLE 6

THE BASIC MEASURING AREAS IN THE FIRM

\begin{tabular}{|c|c|c|c|c|c|c|c|}
\hline \multirow[b]{2}{*}{ ment } & \multicolumn{6}{|c|}{ frequency } & \multirow[b]{2}{*}{$\begin{array}{c}\text { Element } \\
\text { weight }\end{array}$} \\
\hline & $\begin{array}{l}\text { Never } \\
\text { (1) }\end{array}$ & $\begin{array}{l}\text { Rarely } \\
\text { (2) }\end{array}$ & Somehow(3) & $\begin{array}{l}\text { big } \\
\text { extent } \\
\text { (4) }\end{array}$ & $\begin{array}{c}\text { Always } \\
(5)\end{array}$ & Total & \\
\hline $\begin{array}{l}\text { 1. Human } \\
\text { resources }\end{array}$ & 11 & 6 & $\underline{23}$ & 16 & 20 & 76 & 3.4 \\
\hline 2. Materials & 8 & 2 & 7 & $\underline{30}$ & 29 & 76 & 3.9 \\
\hline 3-equipments & 7 & 2 & 15 & $\underline{33}$ & 19 & 76 & 3.7 \\
\hline $\begin{array}{l}4 \text { information } \\
\text { technology }\end{array}$ & 13 & 5 & $\underline{28}$ & 21 & 9 & 76 & 3.1 \\
\hline 5. product & 6 & 0 & 5 & 18 & $\underline{47}$ & 76 & 4.3 \\
\hline
\end{tabular}

Table (6) reveals that the construction firms in general (whether applying QMS or not) put great emphasis and control in the areas directly related to money such as (materials, equipments and product), while giving less care to human resources and information technology (which indirectly deal with money).

A cross-tabulation was constructed to measure the correlation between measuring performance in the basic areas in the construction firms and each of; firm type, specialty, size, experience; applied QMS and its level of application. The Pearson chi-square was used to measure that correlation. Measures of association are displayed in Table (7).

From the tabulated statistics it can be noticed that:

- The applied QMS has an influence on the degree of measuring all areas except for the materials. This reaffirms the concluded result earlier according to the respondents' opinions in Figure (5) which shows that performance improvement increasing as the level of QMS application increases. Also it is noticed that there are high correlations especially with areas that used to get less attention (human resources and information technology), which reveals the role of QMS in improving performance measurements.

- Not surprisingly, both the type and work type of the firm are correlated to the degree of measuring 
performance for the materials and the product, while the degree of measuring performance for the equipment and information technology is influenced by the firm experience.

TABLE 7

CORRELATION BETWEEN THE QMS IMPLEMENTATION AND THE BASIC AREAS IN ECFS

\begin{tabular}{|c|c|c|c|c|c|c|}
\hline \multirow{2}{*}{$\begin{array}{c}\text { firm } \\
\text { characteristic }\end{array}$} & \multirow{2}{*}{$\begin{array}{c}\text { pearson } \\
\text { chi square }\end{array}$} & \multicolumn{5}{|c|}{ The basic areas of construction company } \\
\hline & & $\begin{array}{l}\text { human } \\
\text { resource }\end{array}$ & materials & equipment & $\begin{array}{l}\text { information } \\
\text { technology }\end{array}$ & product \\
\hline \multirow{2}{*}{ Company type } & value & 23.576 & 32.904 & 12.08 & 17.636 & 21.072 \\
\hline & $\begin{array}{l}\text { Approx. } \\
\text { Sig. }\end{array}$ & $\underline{0.023 *}$ & $\underline{0.001^{*}}$ & 0.439 & 0.127 & $\underline{0.012 *}$ \\
\hline \multirow[b]{2}{*}{ Experience } & value & 17.347 & 18.384 & 22.364 & 29.806 & 5.304 \\
\hline & $\begin{array}{l}\text { Approx } \\
\text { Sig. }\end{array}$ & 0.137 & 0.105 & $\underline{0.034 *}$ & $\underline{0.003 *}$ & 0.807 \\
\hline \multirow[b]{2}{*}{ work type } & value & 30.469 & 124.23 & 32.522 & 53.954 & 61.316 \\
\hline & $\begin{array}{l}\text { Approx } \\
\text { Sig. }\end{array}$ & 0.94 & $\underline{0 *}$ & 0.899 & 0.145 & $\underline{0.002 *}$ \\
\hline \multirow[b]{2}{*}{ Work size } & value & 15.368 & 25.808 & 12.812 & 24.665 & 10.344 \\
\hline & $\begin{array}{l}\text { Approx. } \\
\text { Sig. }\end{array}$ & 0.498 & $\underline{0.057 * *}$ & 0.686 & $\underline{0.076 * *}$ & 0.586 \\
\hline \multirow[b]{2}{*}{ QMS } & value & 38.064 & 16.79 & 29.947 & 40.826 & 23.183 \\
\hline & $\begin{array}{l}\text { Approx } \\
\text { Sig. }\end{array}$ & $\underline{0.009 *}$ & 0.667 & $\underline{0.071 * *}$ & $\underline{0.004 *}$ & $\underline{0.08 * *}$ \\
\hline \multirow{2}{*}{$\begin{array}{l}\text { Level of } \\
\text { application }\end{array}$} & value & 24.251 & 23.976 & 21.644 & 25.813 & 18.242 \\
\hline & $\begin{array}{l}\text { Approx } \\
\text { Sig. }\end{array}$ & 0.232 & 0.243 & 0.36 & 0.172 & 0.25 \\
\hline
\end{tabular}

: correlation is significant at 0.05 level

$* *$ : correlation is significant at 0.1 level

\section{THE PROPOSED MODEL}

The concluded relations directed the study to develop a model for MP in ECF. The model is not aimed to be applied at the industry level neither at the project level however it is aimed to be applied at the firm level at which the study took place. The purpose of the proposed model is to strengthen the weak points in the process of MP in order for them to be consistent with total quality management principles. Therefore the model puts more emphasis on continuous improvement, customer satisfaction and human resources in addition to ensuring the importance of the measures that are financial and market oriented. The model is based on the set of indicators that has been derived from the analysis of the real practices of measuring performance in Egyptian construction companies.

The model is structured to answer two main questions: first, what to measure ,through identifying the elements of measuring performance from the international models of QMS and different approaches for identifying performance measures [9], second, how to measure, through determining the corresponding indicators from real practice. The suggested point system has been developed by the integration of the elements' importance according to the responders' opinions and the real practice for these elements which were determined through respondents' agreements on their indicators implementation in ECFs as shown in Table (8).
Following is the mathematical analysis of the model development

1. Calculating the importance level (IL) for each element by dividing the RII for the element by the sum of all indices:

$$
\text { ILi = RIIi / } \sum \text { (RIIi) }
$$

Where:

$\mathrm{IL}_{\mathrm{i}}=$ the element's i importance level (target level)

$\mathrm{RII}_{\mathrm{i}}=$ relative important index of element $\mathrm{i}$. (Table (3)).

$\mathrm{i}=$ No. of elements $(\mathrm{i}=1$ to 10$)$

For example, the element "top management and leadership": $\mathrm{IL}_{1}=(0.85 / 6.8) \times 100=12.5 \%$

2. Determining the percent of real practice ( PrJ )for each indicator

Where:

The percent of each indicator $=$ its frequency divided by No. of total response (76 companies.)

And $\mathrm{J}=$ No. of indicators $(\mathrm{J}=1$ to 47$)$

For example the $\operatorname{Pr}_{J}$ for "planning for change" $=(51 / 76 \times$ 100) $=67.1 \%$.

3. Determining the integrated weight for the indicators (which is obtained by an integration of the importance level of the element and the real practice of its indicators) $\mathrm{WcJ}=\mathrm{ILi} \times \operatorname{PrJ}$

Where:

$\mathrm{Wc}_{\mathrm{J}}=$ integrated weight for the indicators.

For example the indicator "planning for change"

$\mathrm{Wc}_{\mathrm{J}}=(12.5 \% \times 67.1 \%) \times 100=8.4$

4. Determining the integrated weight of each element $\left(\mathrm{Wc}_{\mathrm{i}}\right)$ as the following :

$\mathrm{Wc}_{\mathrm{i}}=\sum\left(\mathrm{Wc}_{\mathrm{J}}\right)$

For example, the element "Top management and leadership"

$\mathrm{Wc}_{\mathrm{i}}=\sum(8.4+6.7+4.3+3.1)=22.5$

5. Determining the performance level for each element $\left(\mathrm{PL}_{\mathrm{i}}\right)$

Where:

$\mathrm{PL}_{\mathrm{i}}=\mathrm{Wc}_{\mathrm{i}} / \sum \mathrm{Wc}$

For example the element "top management and leadership $\mathrm{PL}_{\mathrm{i}}=22.5 / 200=0.112$

6. To obtain a point system that sums up to an integer and to be comparable with the world models of measuring performance the result of each element has been multiplied by (1000). So in the following example for element "top management and leadership"

$\mathrm{PLi}=0.112 * 1000=112$

7. Determining the performance level (PL) for the firm, Where: $\mathrm{PL}=\sum \mathrm{PL}_{\mathrm{i}}$ 


\section{A. How to apply the suggested model}

Column (7) and (8) in Table (8) display the weight of each element and each indicator in the point system of the proposed model. A simple and easy to use excel sheets has been developed to apply the model, shown in Fig. 4. The first monitor in Fig.6 displays scores of indicators that sum up to the scores of elements to sum up in turn to get the PL of the firm. The second monitor determines the firm classification by applying the IF condition, where the value of PL of the construction firm will identify its classification, hence, the study suggested [9] that the firms' levels of performance to be compared at $\mathrm{PL}=600$. The study has benchmarked the PL of ECFs using the criteria of MBNQA (Malcolm Baldrige National Quality Awards) and (European Quality Awards) [9]. The evaluated scores were found to be 661 and 612 for MBNQA and EQA consequently. This benchmarking has been done using the results of a survey that investigated the current status of performance of ECFs. Based on this, the classification for firm performance is:

$$
\begin{array}{lll}
\mathrm{PL}=1000 & & \\
1000>\mathrm{PL}>600 & \begin{array}{l}
\text { best practice } \\
\text { good practice } \\
\mathrm{PL}<600
\end{array} & \text { needs improvement }
\end{array}
$$

Moreover, the value of the performance level for each element is then allocated on the standard radar that displays the weight of each element in the point system as shown in the third monitor for the visual comparison, which displays in a glance the weak points.

The model reveals the level of firm performance that helps the firm to identify the weak points against the strong ones, confirm the priorities and identify new opportunities for improving.

\section{B. Model verification}

The model verification has been accomplished by designing a questionnaire to investigate the opinions of experts in the construction field about the proposed model applicability and practicality in the ECFs. Therefore, the questionnaire was designed [9] with a scale from 1 to 4 (1 the best choice and 4 the worst), then it was distributed through a structured sample of experts (their experience ranges from 17 years to 33 years) in this field. The sample is selected to include the ECFs that implement QMS and practice measuring performance in their firms.

The questionnaire was designed to verify the following:

- The efficiency of the proposed elements in measuring performance in Egyptian construction companies

- The ability of the indicators to express the performance of each element, and the practicality of measuring them as well.

- Exploring to what extent the point system is effective in measuring performance in Egyptian construction companies.
- Finding out to what extent the proposed model is applicable and practical, and identifying the obstacles that would obstruct applying the model, and how they can be overcome.

Responses from ten professionals were collected then coded to be analyzed using SPSS and it was found that:

$1-80 \%$ of respondents found the elements of the model either enough or completely enough to measure the performance of the construction companies.

2-The majority of respondents found the developed point system consistent enough with the elements' importance and their effect in measuring performance. This is based on the mean score of their responses ranges from 1.3 to 2.3 in a scale from 1 to 4 , which are considerably positive reactions.

3-In their response to the efficiency of suggested indicators, the mean scores of responses ranged from 1.1 to 2.3 , which indicates an agreement among the majority that the indicators of each element are sufficient enough to measure that element and consequently the model is reliable for measuring the performance of construction companies in Egypt. Also values of standard deviation were small for most of the elements which reflects the small variation in the experts' opinions.

$4-40 \%$ of respondents believe that the suggested indicators can be completely measured, and the others $(60 \%)$ find these indicators are measurable to a large extent. On the other hand, no one find them nonmeasurable, the previous results insure that the selected indicators for model's elements are sufficient and practical for measuring the performance of construction firms in Egypt.

5-When asking about the efficiency of the point system, the majority of respondents $(90 \%)$ agree that the point system can be used efficiently to measure the performance in ECFs, where half of respondents believe that the point system is completely efficient in measuring performance in construction firms in Egypt. On the other hand, only $10 \%$ see the point system as fairly efficient;

6-70\% of respondents find the model "applicable" and $30 \%$ find that it can be applied efficiently. Also the mean score of the responses is 1.7 with small standard deviation (0.483) referring to a high and consistent satisfaction from the experts to the model's applicability. 


\begin{tabular}{|c|c|c|c|c|c|c|c|}
\hline \multirow[b]{2}{*}{ Element } & \multirow[b]{2}{*}{ Corresponding indicators } & \multirow[b]{2}{*}{ 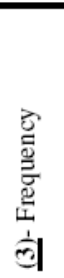 } & \multirow[b]{2}{*}{ 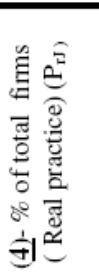 } & \multicolumn{2}{|c|}{ Correlation } & \multicolumn{2}{|c|}{ The model } \\
\hline & & & & 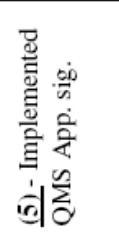 & 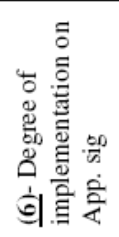 & 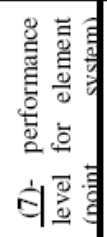 & 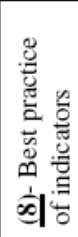 \\
\hline \multirow{4}{*}{$\begin{array}{l}\text { 1-Top } \\
\text { management } \\
\text { leadership }\end{array}$} & 1. Planning for change & 51 & $67.1 \%$ & 0.445 & 0.25 & \multirow[t]{4}{*}{112} & \multirow{4}{*}{$\begin{array}{l}28 \\
28 \\
28 \\
28\end{array}$} \\
\hline & 2. Monitor progress. & 41 & $53.9 \%$ & 0.447 & 0.177 & & \\
\hline & 3. Time required for preparing the project quality plan. & 26 & $34.2 \%$ & $0.003 *$ & $0.084 * *$ & & \\
\hline & $\begin{array}{l}\text { 4. Worker's attitude towards the job and the environment } \\
\text { created on the job site. }\end{array}$ & 19 & $25.0 \%$ & 0.409 & 0.588 & & \\
\hline \multirow{8}{*}{$\begin{array}{l}\text { 2- quality } \\
\text { measurement } \\
\text { \& } \\
\text { benchmarking }\end{array}$} & 1. Application of quality management systems. & 29 & $38.2 \%$ & $0.002 *$ & $0.043 \%$ & \multirow[t]{8}{*}{115} & \multirow{8}{*}{$\begin{array}{l}14 \\
14 \\
14 \\
14 \\
14 \\
14 \\
14 \\
14\end{array}$} \\
\hline & 2. Waste percentage in raw materials. & 29 & $38.2 \%$ & 0.318 & 0.227 & & \\
\hline & 3. Proportion of defects & 25 & $32.9 \%$ & 0.35 & 0.168 & & \\
\hline & 4. Overhead cost reduction. & 25 & $32.9 \%$ & $0.008 *$ & $0.086^{* * *}$ & & \\
\hline & 5. Defective rate relative to competitors. & 24 & $31.6 \%$ & 0.111 & 0.406 & & \\
\hline & 6. Trends of quality costs & 17 & $22.4 \%$ & 0.207 & 0.142 & & \\
\hline & $\begin{array}{l}\text { 7. Number of management meeting to review quality } \\
\text { performance. }\end{array}$ & 15 & $19.7 \%$ & 0.345 & 0.461 & & \\
\hline & 8. Quality control/ rework. & 11 & $14.5 \%$ & $0.004 *$ & 0.894 & & \\
\hline \multirow{4}{*}{$\begin{array}{l}\text { 3-process } \\
\text { management }\end{array}$} & 1. Monitoring current costs and budgeted costs. & 52 & $68.4 \%$ & 0.133 & $0.086^{*} *$ & \multirow[t]{4}{*}{120} & 30 \\
\hline & 2. Reduce material handling. & 50 & $65.8 \%$ & $0.049 *$ & $0.046 *$ & & 30 \\
\hline & 3. Time of cycle time. & 36 & $47.4 \%$ & 0.475 & 0.442 & & 30 \\
\hline & 4. Production goals & 25 & $32.9 \%$ & 0.547 & 0.297 & & 30 \\
\hline \multirow{5}{*}{$\begin{array}{l}\text { 4- product } \\
\text { design } \\
\& \\
\text { manufacturing }\end{array}$} & 1. On time completion. & 45 & $59.2 \%$ & 0.614 & $0.026^{*}$ & \multirow[t]{5}{*}{101} & \multirow{5}{*}{$\begin{array}{l}20 \\
20 \\
20 \\
20 \\
20\end{array}$} \\
\hline & 2. Percent complete. & 36 & $47.4 \%$ & 0.85 & $0.036^{*}$ & & \\
\hline & 3. Fitness of use. & 34 & $44.7 \%$ & 0.505 & 0.642 & & \\
\hline & 4. Design quality. & 28 & $36.8 \%$ & 0.051 * * & $0.029 *$ & & \\
\hline & 5. Percentage of repeat business. & 13 & $17.1 \%$ & 0.47 & 0.897 & & \\
\hline \multirow{3}{*}{$\begin{array}{l}\text { 5-employee } \\
\text { training \& } \\
\text { empowerment }\end{array}$} & 1- Working as a team. & 46 & $60.5 \%$ & 0.228 & 0.189 & \multirow[t]{3}{*}{53} & 18 \\
\hline & 2. Percentage of trained employees to total. & 35 & $46.1 \%$ & 0.086 *** & 0.155 & & 18 \\
\hline & 3. Employee relationship. & 17 & $22.4 \%$ & 0.859 & $0.077 *$ & & 18 \\
\hline \multirow{3}{*}{ 6- safety } & 1. Hiring the trained and specialist workers or employees. & 47 & $61.8 \%$ & 0.906 & $0.011^{*}$ & $\overline{43}$ & 14 \\
\hline & 2. Accidents, frequency. & 28 & $36.8 \%$ & $0.001 *$ & $0.028 *$ & & 14 \\
\hline & 3. Accidents, categories. & 23 & $30.3 \%$ & 0.357 & 0.188 & & 14 \\
\hline & 1. Gross profit, margin. & 50 & $65.8 \%$ & 0.06 *** & 0.546 & 95 & 32 \\
\hline $\begin{array}{l}\text { 7- productivity } \\
\text { \& finance }\end{array}$ & $\begin{array}{l}\text { 2. Productivity indictors of (labor, material, equipment } \\
\text { and employee). }\end{array}$ & 40 & $52.6 \%$ & 0.907 & $\underline{0.055 * *}$ & & 32 \\
\hline & 3. Return on employed. & 34 & $44.7 \%$ & 0.907 & 0.369 & & 32 \\
\hline & 1. Resources on time with good specifications. & 47 & $61.8 \%$ & 0.335 & 0.391 & 142 & 18 \\
\hline & 2. Budget and resources. & 44 & $57.9 \%$ & 0.473 & 0.232 & & 18 \\
\hline & $\begin{array}{l}\text { 3. Total duration of breakdown times that results in } \\
\text { stopping the works. }\end{array}$ & 30 & $39.5 \%$ & 0.38 & 0.272 & & 18 \\
\hline & 4. Market researches. & 27 & $35.5 \%$ & 0.813 & 0.09 *** & & 18 \\
\hline 8- resource & 5-Percentage of waste in raw materials due to bad storage. & 24 & $31.6 \%$ & 0.462 & 0.325 & & 18 \\
\hline & 6. Maintenance plans. & 23 & $30.3 \%$ & $0.005 *$ & 0.225 & & 18 \\
\hline & $\begin{array}{l}\text { 7. Monitoring the productivity changes by the amounts of } \\
\text { materials, tools, and equipment expended during } \\
\text { construction }\end{array}$ & 12 & $15.8 \%$ & 0.881 & 0.426 & & 18 \\
\hline & $\begin{array}{l}\text { 8. Lost time for waiting materials or equipments or } \\
\text { people. }\end{array}$ & 6 & $7.9 \%$ & 0.331 & 0.679 & & 18 \\
\hline 9- supplier & 1- Material availability on time with good specifications. & 56 & $73.7 \%$ & 0.855 & $0.022 *$ & 55 & 18 \\
\hline quality & 2- Supplier relations. & 28 & $36.8 \%$ & 0.93 & $0.076^{*}$ & & 18 \\
\hline management & 3- Number of suppliers. & 26 & $34.2 \%$ & 0.892 & 0.111 & & 18 \\
\hline & 1- Delivery on time. & 60 & $78.9 \%$ & 0.743 & 0.41 & 165 & 27 \\
\hline & 2- Meeting the Customer requirements. & 51 & $67.1 \%$ & 0.143 & 0.117 & & 27 \\
\hline 10- customer & 3- Closer to customer. & 39 & $51.3 \%$ & 0.888 & 0.122 & & 27 \\
\hline & 4- No. or percent of complaints. & 23 & $30.3 \%$ & $0.001 *$ & 0.229 & & 27 \\
\hline & 5- Time and cost of handling these complaints & 19 & $25.0 \%$ & 0.415 & 0.212 & & 27 \\
\hline & 6-external distribution channels & 11 & $14.5 \%$ & $0.016^{*}$ & 0.594 & & 27 \\
\hline TOTAL & & & & & & 1000 & 1000 \\
\hline
\end{tabular}

\footnotetext{
: correlation is significant at 0.05 level
}

**: correlation is significant at 0.1 level 


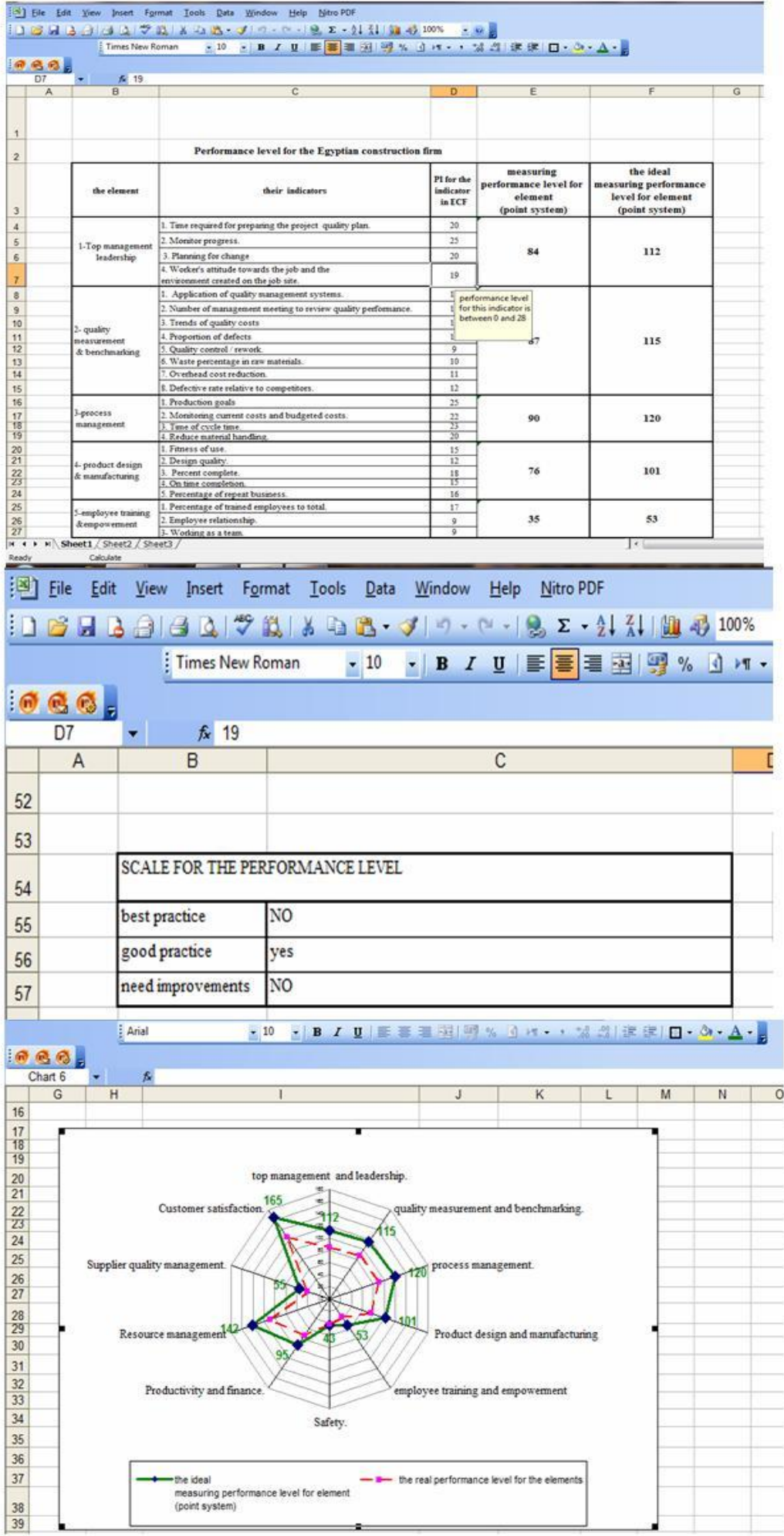

1- enter the score for the real practice of each indicator against the specified value.

2-Automaticaly the PL for the element will appear (sum of the indicators' scores).

3- Automatically the PL for the firm will appear( sum of the elements' scores).

4- According to IF condition the classification of the level of performance for that firm will appear in this box.

5- The value of real performance level is represented on radar chart for each element against the values determined in the point system.

FIGURE 4

APPLYING THE MODEL USING EXCEL SHEETS 
Obstacles facing the developed model

- $\quad 70 \%$ of the experts see that lack of commitment of top management is a major obstacle.

- Also $60 \%$ agree that unavailability of data is a main obstacle against applying the model effectively.

- Another 70\% see that training is needed for model application.

- However, $10 \%$ of respondents see no obstacles for applying the model.

- $\quad 80 \%$ of responses range between that the obstacles are totally manageable and that they can be handled to a large extent. Only $20 \%$ of respondents see that the obstacles will need more effort to be overcome.

\section{PAPER LIMITATIONS}

The model can be fairly applied to any medium to large firm that adopt a QMS in Egypt, where the sampling has occurred in a region that represents most of these firms.

\section{CONCLUSIONS}

The research is trying to explore the influence of implementing QMS in Egyptian Construction Firms on MP. The real practice of all sampled firms (either adopting QMS or not) was investigated and the results showed that, in general the firms put more emphasis on the quantitative objective measures rather than on the qualitative and subjective ones. However, correlation tests revealed a strong relation between QMS implementation and the qualitative measuring elements and their corresponding indicators which insures the positive impact of QMS on firm performance. Accordingly, the study developed a model for measuring performance that helps to strengthen weak points in the current practice and enhance measuring performance by the means of QMS principals. The model operates on the basis of the point system that enables the ECF to benchmark its performance. The study also introduces a simple way of applying the proposed point system through excel sheets and standard Radar. The model has been verified by means of another questionnaire that was answered by a group of experts. The verification results showed that the model can be applied effectively. And the obstacles of its implementation can be overcome by training, data gathering and analysis, and prior to all, support and commitment of top management.

\section{REFERENCES}

[1] J. Oakland, "Total Quality Management", $3^{\text {rd }}$ ed., Elsevier Butterworth Heinemann, 2003.

[2] M. Abd Elhamid, "The Development of Quality Management Systems for the Construction Industry in Egypt", Ph.D., Faculty of Engineering, Helwan University, Cairo, Egypt, pp. 62-80, 2002.

[3] L. Alarcon, D. Ashley, "Modeling project performance for decision making", Journal of Construction Engineering and Management, vol. 122, no. 3, pp. 265-273, 1996.

[4] R. Eccles, "The performance measurement manifesto", Harvard Business Review, vol. 69, no. 1, pp. 131-137, 1991.

[5] R. Abdel-Razek, "Performance Measurement for Construction Firm Using Benchmarking", Proceedings of Symposium, Productivity and performance measurement, Housing and Building National Research Center, Cairo, Egypt, pp. 20-35, May 2006.

[6] R. Cox, R.R.A. Issa, D. Ahrens, "Management's Pereception of Key Performance Indicators for Construction", Journal of Construction Engineering and Management, vol. 129, no. 2, pp. 142-151, 2003.

[7] J. Motwani, "Critical factors and performance measures of TQM", The TQM Magazine, vol. 13, no. 4, pp. 292-300, 2001.

[8] A. Mossallam, "Developing \& Implementing Non-Traditional Techniques in upgrading The Performance Level of Egyptian contracting firms", Ph.D., Faculty of Engineering, Cairo University, Egypt, pp. 14-28, November 2002.

[9] S. Hassan, "Measuring performance in construction firms concerning quality management systems implementation", M.Sc., Faculty of Engineering - Shoubra, Benha University, Cairo, Egypt, 2009.

[10] G. Israel, "Determining sample size", PEOD6, one of a series of the program evaluation and firmal development, Florida University, November 1992.

[11] F.D.K. Fugar, A.B. Agyakwah-Baah, "Delays in building construction projects in Ghana", Australasian Journal of Construction Economics and Building, vol. 10, no. 1/2, pp. 103116, 2010. 